The length of the spindle in Fig. 4 (just on the point of undergoing segmentation) is about four times its diameter; a ratio which is considerably greater than in the three preseding figures, and which approaches that known to hold in the case of an unstable liquid cylinder.

The rate of outflow from the tube is in each case stated under the photograph.

The knitting-pin was then replaced by a glass tube, closed at its upper end, but connected below with a manometer, which was put into connection with the interior of the various bubbles by mean of a small hole previously blown in the side of the tube near its upper extremity. The pressure inside the bubbles was always found to be very nearly atmospheric, an excess of about I $\mathrm{mm}$. of water being the greatest noted.

Another form of apparatus gave striking results.

A -1 tube was supported with the cross piece vertical, and the upper opening was closed with a cork into which a stiff wire was driven, so that it hung centrally, with its other end projecting a little from the lower opening of the tube.

The circular disc was attached to this projecting wire, and was then exactly in the path of the issuing stream of water which was admitted by the side tube.

By properly regulating the velocity of the water a series of surfaces similar to those produced by the former method can be obtained, but the adjustments are not so easily controlled (Fig. 6).

II is curious to note how the water constituting the walls of the bubble reunites into a single stream which falls from its base.

King Edward's School, Birmingham, May 28. T. J. BAKER.

\section{THE INTERNATIONAL CATALOGUE OF} SCIENTIFIC LITERATURE.

$I_{N}$ view of the proceedings at the recent third International Conference, of which the Acta are printed on another page, there can be little doubt that the ultimate execution of this important enterprise is now assured. Prior to the meeting: some of us, perhaps, vaguely feared that the foreign delegates would come prepared to suggest all sorts of difficulties, if not to announce the unwillingness of the countries they represented to take any part in the work; but nothing of the kind occurred: all came bent on securing success; not a word was uttered in depreciation of any of the proposals brought under consideration; and all present may be said to have taken an enthusiastic interest in carrying the proceedings to a satisfactory issue. Every one was of opinion that if a fair beginning can once be made, the importance of the work is so great; it will be of such use to scientific workers at large; that it will rapidly grow in favour and soon secure that wide support which is not yet given to it simpiy because its character and value are but imperfectly understood. Therefore, all were anxious that a beginning should be made.

It has been estimated that if 300 sets or the equivalent are sold. the expenses of publication will be fully met. As the purchase of more than half this number was guaranteed by France, Germany, Italy, Norway, Switzerland and the United Kingdom, the Conference came to the conclusion that the number likely to be taken by other countries would be such that the subscriptions necessary to cover the cost of the catalogue would be obtained.

The resolution arrived at after this opinion had been formed, "That the catalogue include both an author's and a subject index, according to the schemes of the Provisional International Committee," must, in fact, be read as a resolution to establish the catalogue.

Of the countries represented at the various Conferences, excepting Belgium, not one has expressed any unwillingness eventually to cooperate in the work. Unfortunately, neither the United States nor Russia was officially represented on the present occasion. The attempts that have been made to induce the Government in the United NO. I 6OO, VOL. 62]
States to directly subsidise the catalogue have not been successful : but that the United States will contribute its fair share, both of material and of pecuniary support, cannot be doubted. There as here private or corporate enterprise must undertake much that is done under Government auspices in Europe. As to Russia, the organisation of scientific workers there has been so little developed that it is very difficult to secure their attention, and probably our Russian colleagues are as yet but very imperfectly aware of what is proposed. The importance of Russian scientific work is so great, however, that it stands to reason that it must be fully considered; and it may be supposed that Russia will join when she becomes acquainted with what is proposed and what is required of her.

A Provisional International Committee has been ap. pointed, which will take the steps now necessary to secure the adhesion and cooperation of countries not yet pledged to support the scheme.

Originally, it was proposed to issue a card- as well as a book-catalogue, but on account of the great additional expense this would involve, and as the Americans in particular have not expressed themselves in favour of a card issue, it is resolved to publish the catalogue, for the present, only in the form of annual volumes.

From the outset great stress has been laid on the preparation of subject indexes which go behind the titles of papers and give fairly full information as to the nature of their contents. Both at the first and the second International Conference this view met with the fullest approval. Meanwhile, the action of the German Government has made it necessary to somewhat modify the original plan. In Germany, a regional bureau will be established, supported by a Government subvention, and it is intended that the whole of the German scientific literature shall be catalogued in this office; no assistance will be asked from authors or editors or corporate bodies. In such an office it will for the present be impossible to go behind titles; consequently, only the titles of German papers will be quoted in the catalogue. In the first instance, some other countries may prefer to adopt this course on the ground of economy. But in this country, at least, the attempt will be made to deal fully with the literature, and the cooperation of authors and editors will be specially invited. An author may not always be best able to judge which are the most important points in his paper to be noted in an index, but the experience gained in the Royal Society during several years past has shown that authors furnish most valuable information, and that their suggestions are easily reduced into shape. A full code of instructions for the use of the regional bureaux is now being prepared under the auspices of the Provisional International Committee.

The catalogue is to be published annually in seventeen distinct volumes. The collection of material is to commence from January I, I90r. As it will be impossible to print and issue so many volumes at once, it is proposed to publish them in sets of four or five at quarterly in. tervals. During the first year, parts covering shorter periods will be prepared, so as to make the subsequent regular issue possible of volumes in which the literature published during a previous period of twelve months is catalogued. Valuable opportunity will thus be given from the outset of gaining experience both in the preparation and use of the catalogue.

That many difficulties will be encountered in carrying the work out cannot be doubted ; but if scientific workers generally will but refiect on the inestimable value of accurate classified subject indexes, they cannot but see that it will be to their great advantage to do all in their power to further the enterprise. If the attempt fail, it will only be because those on whose behalf it is undertaken are blind to their own interests.

H. E. A. 